\title{
Prevalence of Urinary Tract Infection and Antibiotic Susceptibility Pattern to Urinary Pathogens in Kathmandu Medical College and Teaching Hospital, Duwakot
}

\author{
Pradhan $B,^{1^{*}}$ Pradhan $S B^{2}$
}

\section{Affiliation}

1. Senior Registrar, Department of Emergency Medicine, Kathmandu Medical College Teaching Hospital, Nepal

2. Associate Professor, Department of Pathology, Kathmandu Medical College Teaching Hospital, Nepal

\section{ARTICLE INFO}

Article History

Received : 01 April, 2017

Accepted : 25 April, 2017

Published : 30 April, 2017

(C) Authors retain copyright and grant the journal right of first publication with the work simultaneously licensed under Creative Commons Attribution License CC - BY 4.0 that allows others to share the work with an acknowledgment of the work's authorship and initial publication in this journal.

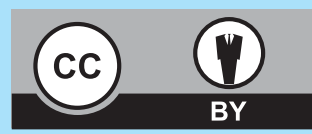

ORA 20

* Corresponding Author

Dr. Binita Pradhan Senior Registrar

Department of Emergency Medicine Kathmandu Medical College Teaching Hospital, Nepal Email: binita_pradhan02@yahoo.com

\section{Citation}

Pradhan B, Pradhan SB. Prevalence of Urinary Tract Infection and Antibiotic Susceptibility Pattern to Urinary Pathogens in Kathmandu Medical College and Teaching Hospital, Duwakot BJHS 2017; 2 (1) 2 : 134-137.

\section{ABSTRACT}

\section{Introduction}

In developing countries, urinary tract infections (UTIs) are one of the most commonly diagnosed disease among the patient seeking medical service and being treated with empirical antibiotics which causes resistance.

\section{Objective}

To find out the prevalence of urinary tract infection and sensitivity pattern of antibiotics among bacterial pathogens isolated in patients attending Kathmandu Medical College Teaching Hospital, Duwakot.

\section{Methodology}

All the patients with the clinical suspicion of UTI were sent for urine culture. Prevalence of UTI and urinary pathogens isolated with antimicrobial profile was correlated.

\section{Result}

A total number of 1735 clinically suspected as UTI cases were sent for urine culture sensitivity. Total culture positive were 239 (13.8\%). The majority of isolates were from female patients comprising 180 (75\%). The most common pathogenic microorganism isolated was E.coli (79.1\%). Second most common organism was Klebsiella (11.7\%) followed by Citrobacter (3.34\%) and Proteus (2.92\%). The isolated microorganism showed maximum number of sensitivity with the antibiotics Ofloxacin and Ciprofloxacin. The isolated microorganism demonstrated resistance with Nalidixic Acid and Co-Trimoxazole.

\section{Conclusion}

Urinary tract infection is a commonly encountered case in general practice. Females are commonly affected than men. The microbiological profile and the antibiotic sensitivity pattern while initiating empirical treatment must be taken into account while planning for the management. Regular supervision of the sensitivity pattern of pathogenic microorganism is mandatory for effective treatment.

\section{KEY WORDS}

Susceptibility, urinary tract infection, uropathogens 


\section{INTRODUCTION}

In developing countries urinary tract infections (UTIs) are one of the most commonly diagnosed disease among the patient seeking medical service with frequency of 180 per $10,000 .{ }^{1}$ Females are more affected compared to men. ${ }^{2}$

UTIs can be categorized as acquired or nosocomial. E.coli is the most common organism responsible for UTI in both community acquired and nosocomial. Klebsiella and Proteus are other responsible pathogens responsible in community acquired infection and in nosocomial are Pseudomonas, Proteus, and Enterobacter. ${ }^{3}$

Increasing resistance has become the main concern due to misuse of antibiotics. General Practitioners should take into account about the microbiological profile and the antibiotic sensitivity pattern during management. ${ }^{4}$ So, it is necessary to look for the most sensitive antibiotics for proper treatment for the UTIs in general practice. ${ }^{5}$

This study was carried out to find out the prevalence of urinary tract infection and susceptibility pattern of antibiotics among bacterial pathogens isolated in patients attending Kathmandu Medical College Teaching Hospital, Duwakot.

\section{METHODOLOGY}

This is a cross-sectional study carried out in Kathmandu Medical College Teaching Hospital, Duwakot Hospital for a period of 2 years from January 2015 to December 2016. All the patients suspicious to have urinary tract infection with the history of burning micturition, increased frequency, lower abdominal pain and fever were subjected to urine culture. Bacterial pathogen isolated with antibiotic sensitivity pattern were taken into account and the findings were correlated. Permission was obtained from the institutional review committee.

\section{RESULTS}

Table 1: Prevalence of uropathogen growth in urine culture

\begin{tabular}{|c|c|c|}
\hline Culture finding & Number (\%) & Gender distribution \\
\hline \multirow[t]{2}{*}{ Growth positive } & \multirow[t]{2}{*}{$239(13.8 \%)$} & M-59 \\
\hline & & $\mathrm{F}-180$ \\
\hline \multirow[t]{2}{*}{ Growth negative } & \multirow[t]{2}{*}{$1496(86.2 \%)$} & M-361 \\
\hline & & F-1135 \\
\hline \multirow[t]{2}{*}{ Total } & \multirow[t]{2}{*}{1735 (100\%) } & $M-420$ \\
\hline & & $F-1315$ \\
\hline
\end{tabular}

Figure 1: Gender distribution of positive urine culture isolates

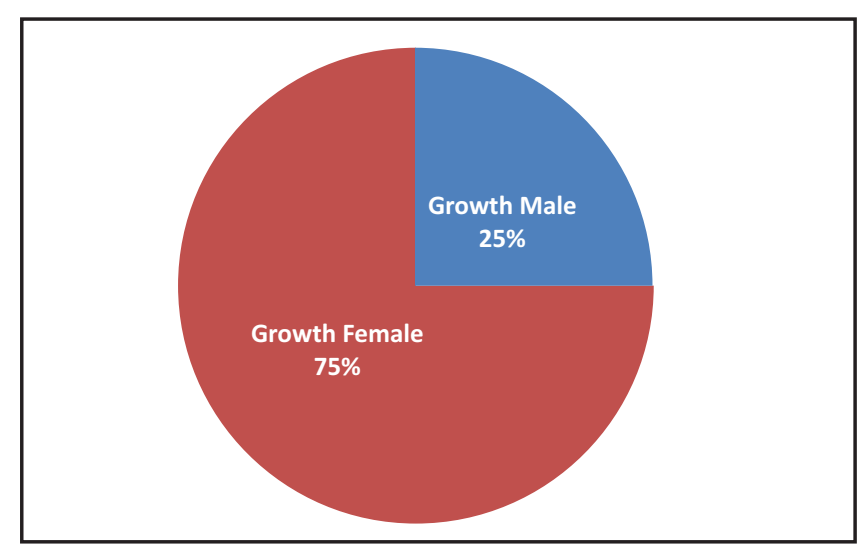

Table 2: Isolated pathogenic microorganism in urine culture

\begin{tabular}{|lll|}
\hline \multicolumn{1}{c}{ Organism } & Number of cases & Percentage \\
\hline E.coli & 189 & 79.1 \\
\hline Klebsiella & 28 & 11.7 \\
\hline Citrobacter & 8 & 3.34 \\
\hline Proteus & 7 & 2.92 \\
\hline Enterobacter & 2 & 0.84 \\
\hline Staphylococcus & 2 & 0.84 \\
\hline Providenia sp & 1 & 0.42 \\
\hline Acinobacter & 1 & 0.42 \\
\hline Pseudomonas & 1 & 0.42 \\
\hline Total & $\mathbf{2 3 9}$ & 100 \\
\hline
\end{tabular}

Figure 2: Antibiotic sensitive pattern of isolated pathogenic microorganism

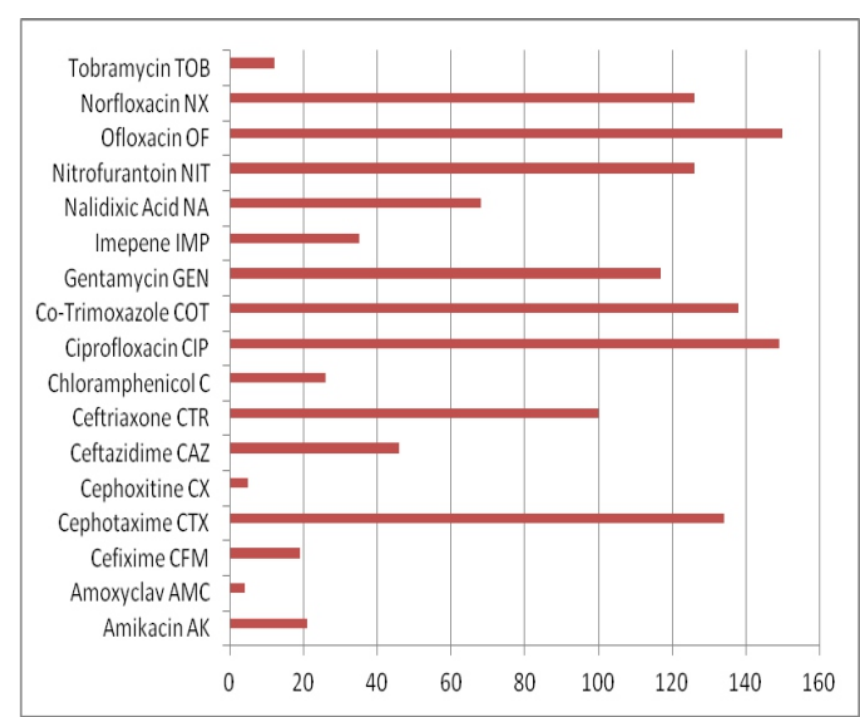


Figure 3: Antibiotic resistance pattern of isolated pathogenic microorganism

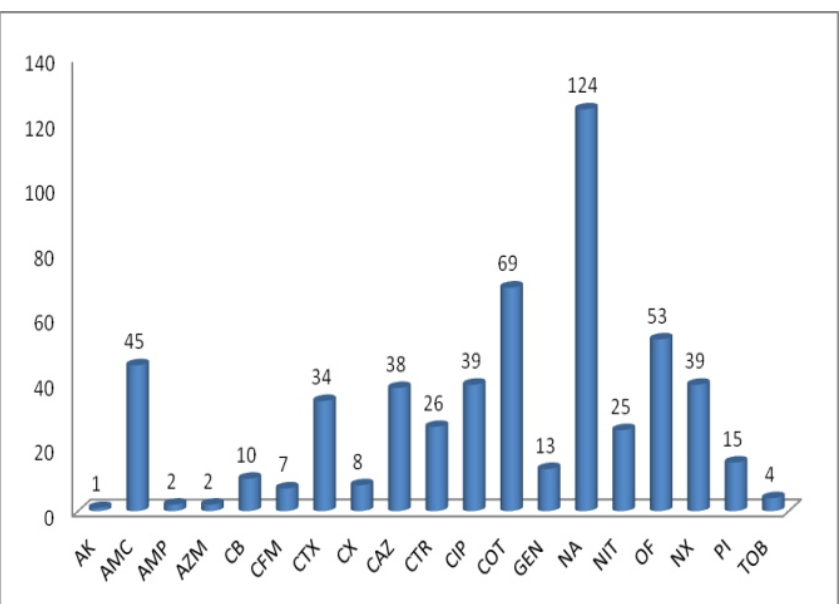

Abbreviations: $\quad A K=A m i k a c i n ; A M C=A m o x y c l a v ; A M P=A m p i c i l l i n$; $A Z M=$ Azithromycin, $C B=$ Carbenicillin; $C F M=C$ efixime; $C T X=$ Cephotaxime; $\mathrm{CX}=$ Cephoxitine; $\quad \mathrm{CAZ}=$ Ceftazidime; $C T R=$ Ceftriaxone; $\mathrm{CIP}=$ Ciprofloxacin; COT=Co-Trimoxazole; GEN=Gentamycin; NA=Nalidixic Acid; NIT=Nitrofurantoin; OF=Ofloxacin; NX=Norfloxacin; $\mathrm{PI}=$ Piperacillin; TOB=Tobramycin

In this study total number of 1735 patients clinically suspected to have UTI were included and sent for urine culture sensitivity test. Among which total of 1315 were female patients and 420 were male patients as shown in table 1.

Out of the total 1735 sample sent for culture sensitivity test, the culture positive were detected in 239 samples (13.8\%).

Out of the culture positive samples, female patients comprise 180 (75.0\%) isolates where as male patients comprise 59 (25.0\%) isolates as shown in figure 1.

The most common pathogenic microorganism found in the culture was E. coli. Second most common organism was Klebsiella followed by Citobacter and Proteus. (Table 2)

In figure 2 the isolated microorganism showed maximum number of sensitivity with the antibiotics Ofloxacin and Ciprofloxacin.

The most common pathogenic microorganism isolated in our study demonstrated resistance with Nalidixic Acid and Co-Trimoxazole. (Figure 3)

\section{DISCUSSION}

Urinary tract infections (UTIs) are one of the most commonly diagnosed disease among the patient seeking medical service in a developing country like Nepal. Females are more affected compared to men.

In our study the prevalence rate of isolation of urinary pathogen were 239 (13.8\%) out of 1735 patients which were enrolled in our study. Subedi $\mathrm{N}$ et al ${ }^{6}$ and Raza S et al ${ }^{5}$ studies showed culture positive in $17.4 \%$ and $19.7 \%$ cases respectively.
Prevalence rate in female patients were seen to be high in comparison to male patients. Female patients comprise 75.0 $\%$ of positive culture isolates in our study. Similar result were found in studies done by Khan $\mathrm{G}$ et $\mathrm{al}^{7}$ showed $77.0 \%$ females compared to $22.8 \%$ male patients with urine culture positive. Study done by Shah LJ et al ${ }^{8}$ reported $49 \%$ female and $11 \%$ male positive samples.

The prevalence in female is higher due to the anatomical structure and lack of secretion produced from prostate which has bactericidal property. ${ }^{7}$

In the most studies done till today, the commonest organism responsible for UTI was found to be E. coli. ${ }^{9}$ The most common pathogenic microorganism isolated in our study was E. coli. Out of 239 positive samples, E.coli was isolated in 189 (79.1\%) cases. The second most common pathogenic microorganism was Klebsiella comprising $11.7 \%$, followed by Citobacter $8.0 \%$ and Proteus $7.0 \%$. This finding is similar to other studies where E. coli are the most frequently isolated pathogenic microorganism causing UTI. ${ }^{3,7,10,11,12}$

The antibiotic susceptibility in our study showed the highest percentage of sensitivity with Ofloxacin (63.0\%) and Ciprofloxacin (62.0\%). In the study done by Raza $S$ et $\mathrm{al}^{5}$ showed the most sensitive antibiotic was found to be Amikacin. Subedi $\mathrm{N}$ et $\mathrm{al}^{6}$ study showed highest number of susceptibility with Piperacillin-Tazobactum and Ceftriaxone. In contrast to our study Ciprofloxacin was resistance of $88 \%$ in study done by Behera PK et al. ${ }^{12}$ The study done by Shaifali et al $^{3}$ showed that highest susceptibilty with Nitrofurantoin (86.9\%), Amoxycillin (69.5\%) and Co-Trimoxazole (60.8\%).

The improper use and easy access of antibiotics as well as poor monitoring of antibiotic sensitivity pattern during the management of UTI in clinical practice, results in high percentage of resistance to commonly prescribed drugs. ${ }^{9,13}$

In our study the most resistance drug to $E$. coli was found to be Nalidixic Acid followed by Co-Trimoxazole. Somashekara SC et $\mathrm{al}^{14}$ also reported the resistance of $\mathrm{E}$ Coli to Cotrimoxazole in $68.8 \%$. Another study done by Haque $\mathrm{R}$ et $\mathrm{al}^{15}$ showed high frequency of resistance to Co-Trimoxazole and Ciprofloxacin. In contrast to our study, Humayun $\mathrm{T}$ et $\mathrm{al}^{16}$ study showed antibiotic sensitivity pattern of Co-trimoxazole was $81 \%$. The resistance profile in the study done by Behera PK et al ${ }^{12}$ were Ciprofloxacin $88.0 \%$ and Ceftriaxone $80.0 \%$. The results draw attention to frightening development of resistance to commonly used drugs.

\section{CONCLUSION}

Urinary tract infection is a commonly encountered case in general practice. Females are commonly affected than men with E. coli being the most common uropathogen. 
Antibiotics such as Nalidixic Acid and Co-Trimoxazole has shown to have limited value and sensitivity to Ofloxacin and Ciprofloxacin have still found to be effective. Increasing antimicrobial resistance to bacteria causing UTI has become a great concern. Regular supervision of the sensitivity pattern

\section{REFERENCES}

1. Bader MS, Hawboldt J, Brooks A. Management of complicated urinary tract infections in the era of antimicrobial resistance. Postgrad Med. 2010;122(6):7-15.

2. Bent $\mathrm{S}$ et al. Urinary Tract Infections, Pyelonephritis, and Prostatitis. In: Longo DL, Kasper DL, Jameson JL, Fauci AS, Hauser SL, Loscalzo J, editors. Harrison's Principle's of Internal Medicine. 18th ed. McGraw Hill: USA; 2012. p 4773-82.

3. Shaifali I, Gupta U, Mahmood SE, Ahmed J. Antibiotic susceptibility patterns of urinary pathogens in female outpatients. N Am J Med Sci. 2012 Apr; 4(4): 163-169.

4. Hummers-Pradier E, Kochen MM. Urinary tract infections in adult general practice patients. Br J Gen Pract. 2002 Sep; 52(482):752-61.

5. Raza S, Pandey S, Bhatt CP. Microbiological analysis microbiological analysis of isolates in Kathmandu Medical College teaching hospital, Kathmandu, Nepal. Kathmandu Univ Med J (KUMJ). 2011 Oct-Dec; 9(36):295-7.

6. Subedi N, Pudasaini S. Bacteriological profile and antibiotic sensitivity pattern in patients with urinary tract infection. Journal of Pathology of Nepal (JPN). 2017 March; Vol. 7 (13); 1066-1069.

7. Khan G, Ahmad S, Anwar S. Frequency of uropathogens in different gender and age groups. Gomal J Med Sci. 2013 June; 11: 20-3.

8. Shah LJ, Vaghela GM, Mahida H. Urinary tract infection: Bacteriological profile and its antibiotic susceptibility in Western India. National Journal of Medical Research (NJMR). Jan - March 2015; Volume 5(1): 71-4

9. Vasudevan R. Urinary Tract Infection: An Overview of the Infection and the Associated Risk Factors. J Microbiol Exp 1(2). 2014 May; 00008. DOI: 10.15406/jmen.2014.01.00008 of pathogenic microorganism is mandatory for effective treatment.

\section{CONFLICT OF INTEREST}

We declare no conflict of interest.

10. Sabir S, Anjum AA, ljaz T, Ali MA, Khan MR, Nawaz M. Isolation and antibiotic susceptibility of $E$. coli from urinary tract infections in a tertiary care hospital. Pak J Med Sci (pjms). 2014; 30(2): 389-392.

11. Tada GD, Gandhi JP, Patel NK. A study on antibiotic related resistance in UTI patients: a comparison between community acquired and hospital acquired E coli. Nat J Com Med. 2012 April-June;3(2):255-8.

12. Behera PK, Panigrahi R, Mishra SN, Tripathy KP. ClinicoMicrobiological Profile of Community Acquired Urinary Tract Infection in The Elderly: A Hospital Based Study Journal of Dental and Medical Sciences. 2016 November; 15(11): 29-34.DOI: 10.9790/0853-1511082934.

13. Divyashanthi CM, Adithiyakumar S, Bharathi N. Study of prevalence and antimicrobial susceptibility pattern of bacterial isolates in a tertiary care hospital. International journal of pharmacy and pharmaceutical sciences. 2015; 7(1): 185-90.

14. Somashekara SC, Deepalaxmi S, Jagannath N, Ramesh B, Laveesh MR, Govindadas D. Retrospective analysis of antibiotic resistance pattern to urinary pathogens in a Tertiary Care Hospital in South India. J Basic Clin Pharma. 2014 September- November; 5 (4):105-8.

15. Haque R, Akter ML, Salam MA. Prevalence and susceptibility of uropathogens: a recent report from a Teaching hospital in Bangladesh.BMC Res Notes. 2015; 8:416.DOI 10.1186/s13104-0151408-1

16. Humayun $T$, Iqbal $A$. The culture and sensitivity pattern of urinary tract infections in females of reproductive age group. Ann Pak Inst Med Sci. 2012; 8(1): 19-22. 